\title{
Use of mobile screening unit for diabetic retinopathy in rural and urban areas
}

\author{
G P Leese, S Ahmed, R W Newton, R T Jung, A Ellingford, P Baines, S Roxburgh, J Coleiro
}

\begin{abstract}
Objectives-To compare the effectiveness of a mobile screening unit with a non-mydriatic polaroid camera in detecting diabetic retinopathy in rural and urban areas. To estimate the cost of the service.

Design-Prospective data collection over two years of screening for diabetic retinopathy throughout Tayside.
\end{abstract}

Setting-Tayside region, population 390000 , area $7770 \mathrm{~km}^{2}$.

Subjects-961 patients in rural areas and 1225 in urban areas who presented for screening.

Main outcome measures-Presence of diabetic retinopathy, need for laser photocoagulation, age, duration of diabetes, and diabetic treatment.

Results-Compared with diabetic patients in urban areas, those in rural areas were less likely to attend a hospital based diabetic clinic (46\% (442) $v$ $86 \%(1054), p<0.001)$; less likely to be receiving insulin (260 (27\%) $v 416(34 \%), p<0.001$ and also after correction for differences in age distribution); more likely to have advanced (maculopathy or proliferative retinopathy) diabetic retinopathy $(13 \%$ (122) $v 7 \%(89), \mathrm{p}<0.001)$; and more likely to require urgent laser photocoagulation for previously unrecognised retinopathy $(1.4 \%$ (13) $v 0.5 \%(6), \mathrm{p}<0.02)$. The screening programme cost $£ 10$ per patient screened and $£ 1000$ per patient requiring laser treatment.

Conclusion-The mobile diabetic eye screening programme detected a greater prevalence of advanced retinopathy in diabetic patients living in rural areas. Patients in rural areas were also more likely to need urgent laser photocoagulation. Present screening procedures seem to be less effective in rural areas and rural patients may benefit more from mobile screening units than urban patients.

Departments of Medicine, Ophthalmology, and Community Medicine, Ninewells Hospital and Medical School, Dundee DD1 9SY

G P Leese, research registrar $\mathrm{S}$ Ahmed, senior registrar $\mathrm{R}$ W Newton, consultant $\mathrm{R}$ T Jung, consultant A Ellingford, ophthalmic photographer

P Baines, consultant ophthalmologist S Roxburgh, consultant ophthalmologist J Coleiro, consultant ophthalmologist

Correspondence to: Dr Leese.

BMF 1993;306:187-9

\section{Introduction}

Non-mydriatic fundal photography is useful for detecting retinopathy in patients with diabetes ${ }^{1-5}$ and has been shown to be effective in identifying previously unrecognised retinopathy when used in the community. ${ }^{6}$ Eleven mobile eye screening units are now in operation throughout the United Kingdom. Although

TABLE I-Results of retinal photography in rural and urban patients. Values are numbers (percentages) of patients

\begin{tabular}{lcc}
\hline & $\begin{array}{c}\text { Rural patients } \\
(\mathrm{n}=915)\end{array}$ & $\begin{array}{c}\text { Urban patients } \\
(\mathrm{n}=1225)\end{array}$ \\
\hline No abnormality & $531(58)$ & $749(61)$ \\
Background changes & $128(14)$ & $168(14)$ \\
Advanced retinopathy & $122(13)$ & $89(7)^{\star}$ \\
Other eye changes & $91(10)$ & $125(10)$ \\
Cataracts or unreadable & $43(5)$ & $94(8)$ \\
New referrals to the eye clinic & $44(4 \cdot 8)$ & $55(4 \cdot 5)$ \\
Laser photocoagulation & $13(1.4)$ & $6(0.5) \dagger$ \\
${ }^{\star} \mathrm{p}<0 \cdot 001, \mathrm{p}<0.02$. & &
\end{tabular}

useful for an initial screening programme, their continued use needs to be evaluated.

Some patients with diabetes, especially those in rural areas, are unable or unwilling to attend a hospital diabetic clinic for retinal screening. General practitioners, however, may not be confident in the use of an ophthalmoscope ${ }^{7}$ since they rarely need to use one. A mobile eye screening unit could help overcome this problem, and fundholding general practitioners may be willing to pay for this service.

\section{Subjects and methods}

A mobile eye screening unit has been operating in Tayside since $1990 .^{\circ}$ Fundi of diabetic patients are photographed with a Canon non-mydriatic polaroid camera (CR4-45NM).

The population density throughout Tayside varies from the densely populated cities of Dundee and Perth to the scattered populations in rural Perthshire and Angus. The total population is 390000 and about 3.5\% (7000) of the urban population are Asian. We identified the postcode areas of patients and categorised them into three groups-namely, urban, rural, or mixed. The presence and severity of retinopathy was compared between patients living in rural and urban areas. Age, duration of diabetes, type of diabetic care (hospital based or community based) and treatment were also recorded. Patients living in mixed postcode areas were not included in this study. Retinal photographs were taken by a trained ophthalmic photographer and photographs were classified into five groups (no abnormality, background changes, maculopathy or proliferative retinopathy, other eye disease, and cataracts, or unreadable) by specialists in diabetes in conjunction with consultant ophthalmologists when required. Only $4 \%$ of photographs were unreadable.

The cost of the service was estimated based on screening 1800 patients a year and includes the salary of an ophthalmic photographer, purchasing and processing film, and the servicing and running costs of the van and camera. Results were analysed by Student's $t$ test and $\chi^{2}$ test. The Mantel-Haenszel statistic was also used. ${ }^{8}$ A deprivation score ${ }^{9}$ was used to compare the relative deprivation or affluence of rural and urban areas. The deprivation score was derived from a combination of four variables (car ownership, social class, male unemployment, and overcrowding).

\section{Results}

A total of 2984 patients were photographed, of whom 1225 lived in urban areas, 961 in rural areas, and 798 in mixed areas. This represented $1.1 \%$ of the rural population and $0.6 \%$ of the urban population. The prevalence of diabetic background retinopathy was the same in rural and urban patients (14\%, table I), but the prevalence of advanced retinopathy (proliferative 
retinopathy or maculopathy) was greater among rural patients than urban patients (13\% (122) $v 7 \%(89)$, $\mathrm{p}<0.001)$. Many of these patients were known to have advanced retinopathy, but some new cases were detected. The prevalence of other eye disease was similar in the two groups (table I). The rate of new referrals to the eye clinic with suspected advanced retinopathy was similar in rural and urban areas $(4 \cdot 8 \%$ (44) $v 4.5 \%$ (55)) but more rural patients than urban patients required urgent laser photocoagulation ( $1 \cdot 4 \%$ (13) v $0.5 \%(6), \mathrm{p}<0.02)$. Ninety nine $(86 \%)$ patients referred to the ophthalmology clinic had advanced retinopathy confirmed, and those who did not receive laser photocoagulation underwent frequent continuing ophthalmic assessment.

Table II shows that there were no differences in duration of diabetes between the two groups. Correction for the small differences in age between the two groups with the Mantel-Haenszel statistic did not affect the results (difference in prevalence of advanced retinopathy $\mathrm{p}<0.001$; differences in rate of laser photocoagulation for previously unrecognised retinopathy $\mathrm{p}=0.02)$. Fewer rural patients than urban patients were receiving insulin $(27 \%(260) v 34 \%(416)$, $\mathrm{p}<0.01$; table III). If the null hypothesis is assumed correct-that is, there is no difference in the preval-

TABLE II-Duration of diabetes and age of patients screened for retinopathy in rural and urban communities. Values are numbers (percentages) of patients

\begin{tabular}{lcc}
\hline & $\begin{array}{c}\text { Rural population } \\
(\mathrm{n}=961)\end{array}$ & $\begin{array}{c}\text { Urban population } \\
(\mathrm{n}=1225)\end{array}$ \\
\hline $\begin{array}{c}\text { Duration of diabetes (years): } \\
1-4\end{array}$ & $455(47 \cdot 3)$ & $560(45 \cdot 7)$ \\
$5-9$ & $231(24 \cdot 0)$ & $322(26 \cdot 3)$ \\
$10-14$ & $124(12 \cdot 9)$ & $161(13 \cdot 1)$ \\
$15-19$ & $62(6 \cdot 5)$ & $83(6 \cdot 8)$ \\
$\geqslant 20$ & $89(9 \cdot 3)$ & $99(8 \cdot 1)$ \\
Age of patient (years): & $14(1 \cdot 5)$ & $16(1 \cdot 3)$ \\
$<20$ & $95(9 \cdot 9)$ & $125(10 \cdot 2)$ \\
$20-39$ & $225(23 \cdot 4)$ & $372(30 \cdot 4)$ \\
$40-59$ & $627(65 \cdot 2)$ & $712(58 \cdot 1)$ \\
$>60$ & & \\
\hline
\end{tabular}

TABLE III-Differences in treatment between patients with diabetes in rural and urban areas. Values are numbers (percentages) of patients

\begin{tabular}{lcc}
\hline Treatment & $\begin{array}{c}\text { Rural patients } \\
(\mathrm{n}=961)\end{array}$ & $\begin{array}{c}\text { Urban patients } \\
(\mathrm{n}=1225)\end{array}$ \\
\hline Diet only & $240(25)$ & $294(24)$ \\
Oral drugs & $461(48)$ & $515(42)$ \\
Insulin & $260(27)^{\star}$ & $416(34)^{\star}$ \\
\hline${ }^{\star} \mathrm{p}<0 \cdot 01$. & &
\end{tabular}

TABLE IV-Observed and expected numbers of patients having laser photocoagulation in rural and urban population. Expected numbers calculated from observed distribution of patients

\begin{tabular}{|c|c|c|c|c|c|c|c|}
\hline & \multicolumn{2}{|c|}{$\begin{array}{c}\% \text { Of overall } \\
\text { diabetic population }\end{array}$} & \multirow{2}{*}{$\begin{array}{c}\text { Observed } \\
\text { No of } \\
\text { patients }\end{array}$} & \multicolumn{2}{|c|}{$\begin{array}{c}\text { Expected } \\
\text { No of patients }\end{array}$} & \multicolumn{2}{|c|}{$\begin{array}{l}\text { Actual No } \\
\text { of patients }\end{array}$} \\
\hline & Rural & Urban & & Rural & Urban & Rural & Urban \\
\hline Diet & 44 & 56 & 1 & 0.4 & 0.6 & - & - \\
\hline Oral drugs & 45 & 55 & 12 & $5 \cdot 4$ & $6 \cdot 6$ & - & - \\
\hline Insulin & 36 & 64 & 6 & $2 \cdot 2$ & $3 \cdot 8$ & - & - \\
\hline All & 44 & 56 & 19 & 8 & 11 & 13 & 6 \\
\hline
\end{tabular}

TABLE $\mathrm{v}$-Observed and expected numbers of patients with advanced retinopathy (maculopathy or proliferative retinopathy) in rural and urban population. Expected numbers calculated from observed distribution of patients

\begin{tabular}{|c|c|c|c|c|c|c|c|}
\hline & \multicolumn{2}{|c|}{$\begin{array}{c}\% \text { Of overall } \\
\text { diabetic population }\end{array}$} & \multirow{2}{*}{$\begin{array}{c}\text { Observed } \\
\text { No of } \\
\text { patients }\end{array}$} & \multicolumn{2}{|c|}{$\begin{array}{c}\text { Expected } \\
\text { No of patients }\end{array}$} & \multicolumn{2}{|c|}{$\begin{array}{l}\text { Actual No } \\
\text { of patients }\end{array}$} \\
\hline & Rural & Urban & & Rural & Urban & Rural & Urban \\
\hline Diet & 44 & 56 & 19 & $8 \cdot 4$ & $10 \cdot 6$ & - & - \\
\hline Oral drugs & 45 & 55 & 100 & 45 & 55 & - & - \\
\hline Insulin & 36 & 64 & 92 & 33 & 59 & - & - \\
\hline All & 44 & 56 & 211 & $86 \cdot 4$ & $124 \cdot 5$ & 122 & 89 \\
\hline
\end{tabular}

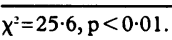

ence of previously unknown advanced retinopathy among rural and urban diabetic patients- the expected number of patients with retinopathy and requiring laser photocoagulation can be calculated from each group. Tables IV and $\mathrm{V}$ show the comparison of observed and expected numbers among the rural and urban patients. The observed differences in the prevalence of retinopathy and need for laser treatment between these two groups remained significant.

Urban areas were less affluent than rural areas as assessed by the deprivation score ${ }^{9}$ (rural areas -2.07 , urban areas 0.44$)$. Patients in urban areas were more likely to attend a hospital clinic $(86 \%$ (1054) v $46 \%$ (442), $\mathrm{p}<0.001)$ : The screening programme in Tayside cost $£ 10$ per patient screened, which is equivalent to $£ 350$ per patient with previously unrecognised sight threatening changes. This represents a cost of $£ 1000$ per patient receiving laser treatment.

\section{Discussion}

Our screening programme covered $0.77 \%$ of the total population of Tayside. The estimated prevalence of known diabetes is $1 \cdot 0-1 \cdot 2 \%$, suggesting that $64-77 \%$ of the diabetic population have been screened. The proportion of the population screened was higher in rural areas $(1 \cdot 1 \%)$ than in urban areas $(0.6 \%)$ and this may be because urban diabetic patients were more likely to attend a hospital diabetic clinic. The greater affluence of rural patients may.explain the better pick up rate in rural areas, but compensating for socioeconomic and ethnic differences between rural and urban areas (which were small) would be expected to increase the differences in retinopathy observed.

A higher proportion of patients with diabetes in rural areas had advanced retinopathy identified by the screening unit compared with urban patients. Rural patients were also more likely to require urgent laser photocoagulation for unrecognised retinopathy. These differences were not attributable to differences in age or duration of diabetes. There are several possibilities to explain this. Firstly, rural patients had more retinopathy or their retinopathy went unrecognised more often. Rural patients tend to be referred later ${ }^{10}$ and the risks of this can be amplified if there are problems in the "referral chain" to the ophthalmology clinic." More urban patients attended a hospital based diabetic clinic and this may be one reason why such patients had less unrecognised retinopathy, ${ }^{7}$ although hospital attendance is not always welcomed or thought necessary by patients. ${ }^{12}$ Secondly, a greater percentage of the population in the rural areas was screened and if the prevalence of diabetes was similar in each area the screening programme may have missed more patients with advanced retinopathy in urban areas. This is, however, unlikely as there were a similar number of patients in each group with background retinopathy. Moreover, the duration of diabetes and the age distribution for both groups were broadly similar suggesting that no participation bias had occurred.

Significantly fewer patients in rural areas were receiving insulin, which may also have influenced the development of advanced retinopathy, ${ }^{13}$ even though insulin treatment does not necessarily reflect better diabetic control. ${ }^{14}$ This difference in prescribing between rural and urban areas was found almost exclusively in patients not attending a hospital diabetic clinic. Urban general practitioners have more direct contact with the hospital clinic, which may have a secondary effect on their management decisions even for patients whom they do not send to the hospital clinic. ${ }^{14}$ Diabetic shared care schemes ${ }^{15-18}$ and diabetic liaison nurses ${ }^{19}$ help facilitate the dispersal of information from the central hospital clinic to general practitioners and families caring for patients with diabetes. ${ }^{20}$ 
There is a demand for these services, ${ }^{721}$ and these facilities are possibly less developed in rural areas. General practitioners have also found intensive courses in diabetes helpful in keeping them up to date and improving their clinical skills. ${ }^{22}$

The salary of the ophthalmic photographer, depreciation of the van and camera, running and servicing costs for the van, and the cost of the film and its processing were all accounted for in the calculation of the cost of the service. At $£ 10$ per patient screened the service is cheaper than all the alternatives. ${ }^{23}$ The costs of transporting patients to the hospital and hospital running costs are not applicable to the mobile eye unit. ${ }^{23}$ The cost of $£ 1000$ for the identification of each patient that required laser photocoagulation is relatively low. Costs could be reduced further by screening more patients per unit time, and we estimate that it should be possible to screen 2500 patients a year once the screening programme is established (our costs are based on screening 1800 per year).

In conclusion, mobile diabetic eye screening units seem to be particularly effective at identifying previously unrecognised retinopathy in rural areas, at a relatively low cost.

1 Williams R, Nussey S, Humphreys R, Thomson G. Assessment of nonmydriatic fundus photography in detection of diabetic retinopathy. $B M \mathcal{F}$ 1986;293:1140-2

2 Taylor R, Lovelock L, Tunbridge W, Alberti K, Brackenbridge $R$, Stephenson $\mathrm{P}$, et al. Comparison of non-mydriatic retinal photography with Stephenson $\mathrm{P}$, et al. Comparison of non-mydriatic retinal photography with
ophthalmoscopy in 2159 patients: mobile retinal camera study. BMF ophthalmoscopy

3 Nathan D, Fogel H, Godive J, Lou P, D'Amico D, Regan C, et al. Role of diabetologist in evaluating diabetic retinopathy. Diabetes Care 1991;14: 26-33.

4 Rogers D, Bitner-Glindzicz M, Harris C, Yudkin J. Non-mydriatic retinal photography as a screening service for general practitioners. Diabetic Med 1990;7:165-7.
5 Higgs E, Harney B, Kelleher A, Reckless J. Detection of diabetic retinopathy in the community using a non-mydriatic camera. Diabetic Med 1991;8. in the

6 Leese G, Newton R, Jung R, Haining $\mathbb{W}$, Ellingford A. Screening for diabetic retinopathy in a widely spaced population using non-mydriatic fundus
nation retinopathy in a widely spaced population using non-

7 Higgs E, Simpson H, Reckless J. General practitioner based diabetic care-district survey. Diabetic Med 1987;4(suppl):577A

8 Snedecor G, Cochran W. Statistical methods. 6th ed. Iowa: Iowa State University, 1967.

9 Carstairs V, Morris R. Deprivation and health in Scotland. Aberdeen: Aberdeen University Press, 1991.

10 Wareham N, Flatman M, Astbury N, Greenwood R. Establishing an eye screening programme in a rural health district. Diabetic Med 1990;7(suppl 2):32A.

11 Jones R, Larizgoita I, Casado L, Barrie T. How effective is the referral chain for diabetic retinopathy. Diabetic Med 1989;6:262-6.

12 Dornan C, Fowler G, Mann J, Markus A, Thorogood M. A community study of diabetes in Oxfordshire. $\mathcal{F} R$ Coll Gin Pract 1983;33:151-5.

13 Kohner E, Aldington S, Nugent $Z$. United Kingdom prospective diabetes study. Retinopathy at entry in the UK prospective diabetes study. Diabetes 1987;36(suppl):42A.

14 Yudkin J, Boucher B, Schopflin K, Harris B, Claff H, Whyte N, et al. The quality of diabetic care in a London health district. $f$ Epidemiol Community Health 1980;34:277-80.

15 Whitford D, Avery A. Barriers to comprehensive diabetic care in the Northern region. Practical Diabetes 1989;6(3):114-6.

16 Hill R. Community care service for diabetics within Poole area. $B M$ 1976;i:1137-9.

17 Reith S. A shared-care option in a semirural area. "Shared care in diabetes." London Update 1985;10:24-30.

18 Tattersall $R$. The future role of the diabetes specialist nurse-responsibility without authority. Diabetic Med 1986;3:166-7.

19 Spathias G. Facilities in diabetic clinics in the UK: Shortcomings and recommendations. Diabetic Med 1986;3:131-6.

20 Challen A, Davies A, Williams R, Baum I. Support for families with diabetic children: parents' views. Practical Diabates 1990;7(1):26-31.

21 Hayes T, Harries J. Randomised controlled trial of routine hospital clinic care versus routine general practice care for type II diabetics. BMf 1984;289: $728-30$

22 Houghton G, Wall D. Does an intensive residential course on diabetes for general practitioners improve the care of diabetes in the practice. Practical Diabetes 1990;7(4):174-8.

23 Sculpher M, Buxton M, Fergusson B, Humphreys J, Altman J, Spiegelhalter D. A relative cost-effectiveness analysis of different methods of screening for diabetic retinopathy. Diabetic Med 1991;8:644-50.

(Accepted 17 November 1992)

\section{The Future of FHSAs}

\section{Developing a research and development strategy for primary care}

\section{Andrew Harris}

This is the third in a series of articles on the future of family health services authorities
Lambeth, Southwark and Lewisham Family Health Services Authority Andrew Harris, director of clinical policy and research

Series editor: Dr Andrew Harris.

$B M f$ 1993;306:189-92
"Research is vital to improve standards of patient care. It increases knowledge and fosters a critical attitude to existing patterns of care and treatment," reported the royal commission on the NHS in 1979.' The report went on to comment on the absence of objective criteria for setting health priorities and to emphasise the need for health service research to be multidisciplinary. Innovation has, however, been largely driven by hospital consultants and scientists with specialist interests in diseases and treatment. Research priorities have reflected this, to the neglect of evaluation of current practice.

Three recent significant changes have created a great opportunity to focus research on the health needs of the population. The first is the creation in 1990 of the purchaser and provider split in the NHS, which gave commissioning authorities (district health authorities and family health services authorities) powers and responsibilities to develop health care strategies and purchasing plans that maintain good health and maximise health gain. The second is the development of medical audit, which encourages practitioners critically to examine current practice. The third is the establishment of a research and development strategy for the NHS in 1991 under the direction of Professor Michael Peckham. Its prime objective is "to see that $\mathrm{R} \& \mathrm{D}$ becomes an integral part of health care so that clinicians, managers and other staff find it natural to rely on the results of research in their day to day decision making and longer term strategic planning."
The strategy is currently being developed by regional health authorities, which have the responsibility to plan a coherent programme. To be successful the regional plan will need to encompass research and development at the grass roots level in communities and primary care settings. This is an enormous challenge for family health services authorities, which should, together with the regional health authority, develop a local strategy for research and development activity in primary care and establish targets for appropriate spending.

\section{Resources}

Most patients are managed in primary care but the vast majority of research publications derive from hospitals. In South East Thames Regional Health Authority about $0.96 \%$ of the NHS spend is on research and development, of which only $0.03 \%$ is recorded as for primary care. Correcting this imbalance should be a priority for family health services authorities. The financial resources proposed by the secretary of state to support the strategy are intended to move over a 5 year period from $0.8 \%$ of the total NHS budget to a target of $1.5 \%$. On a pro rata basis this might make $£ 92.7$ million available to primary and community care.

Only $15 \%$ of $\cdot$ health research is currently funded by the Department of Health or NHS, the bulk being funded by pharmaceutical companies and medical 